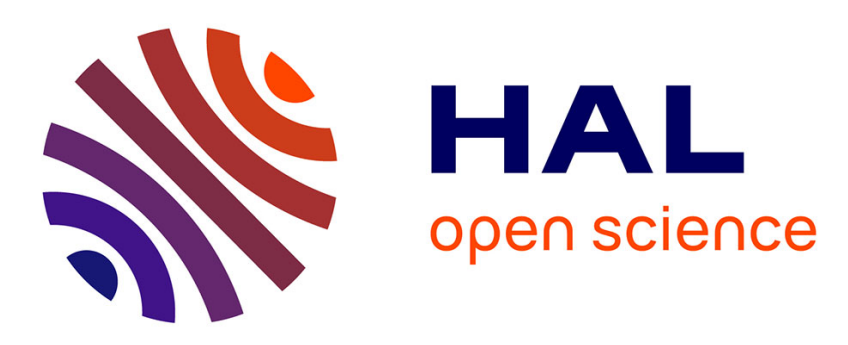

\title{
Synchrotron X-Ray microtomography: a high resolution, fast and quantitative tool for rock characterization.
}

\author{
Elodie Boller, Peter Cloetens, José Baruchel, Paul Tafforeau, Olivier
}

Rozenbaum, Jérémie Pourchez

\section{- To cite this version:}

Elodie Boller, Peter Cloetens, José Baruchel, Paul Tafforeau, Olivier Rozenbaum, et al.. Synchrotron X-Ray microtomography: a high resolution, fast and quantitative tool for rock characterization.. 2006, 9p. hal-00101634

\section{HAL Id: hal-00101634 \\ https://hal-insu.archives-ouvertes.fr/hal-00101634}

Submitted on 27 Sep 2006

HAL is a multi-disciplinary open access archive for the deposit and dissemination of scientific research documents, whether they are published or not. The documents may come from teaching and research institutions in France or abroad, or from public or private research centers.
L'archive ouverte pluridisciplinaire HAL, est destinée au dépôt et à la diffusion de documents scientifiques de niveau recherche, publiés ou non, émanant des établissements d'enseignement et de recherche français ou étrangers, des laboratoires publics ou privés. 


\section{Synchrotron X-Ray microtomography: a high resolution, fast and quantitative tool for rock characterization}

\section{Elodie BOLLER* - Peter CLOETENS* - José BARUCHEL* - Paul TAFFOREAU ${ }^{*}, * *$ _ Olivier ROZENBAUM ${ }^{* * *}$ - Jérémie POURCHEZ*****}

*European Synchrotron Radiation Facility

6 , rue Jules Horowitz

38043 Grenoble cedex, France

boller@esrf.fr

cloetens@esrf.fr

baruchel@esrf.fr

paul.tafforeau@esrf.fr

** Laboratoire de Géobiologie, Biochronologie et Paléontologie Humaine

$40 \mathrm{Av}$. du Recteur Pineau

86022 Poitiers cedex, France

*** CNRS-Institut des Sciences de la Terre d'Orléans

1 A rue de la Férollerie

45071 ORLEANS cedex 2, France

rozenb@cnrs-orleans.fr

****Ecole Nationale Supérieure des Mines de Saint Etienne

158, cours Fauriel

42023 Saint Etienne cedex 2, France

pourchez@emse.fr

ABSTRACT: This article describes the current capabilities of the European Synchrotron radiation Facility (ESRF), and more particularly those of the ID19 beamline, devoted to imaging, for microtomography. Phase contrast, in situ and fast acquisitions, are emphasized, and examples illustrate the possibilities offered by the use of modern SR sources.

RÉSUMÉ: Cet article expose les possibilités actuelles de l'Installation Européenne de Rayonnement Synchrotron (ESRF), et plus en particulier celles de la ligne ID19 dédiée à l' 'imagerie, en ce qui concerne la microtomographie. Les aspects contraste de phase, in situ et acquisition rapide sont soulignés. Des exemples illustrent les possibilités nouvelles.

KEY WORDS: Synchrotron, microtomography, absorption, phase contrast, in-situ, fast acquisitions.

MOTS-CLÉS: Synchrotron, microtomographie, absorption, contraste de phase, acquisitions rapides, in-situ. 


\section{Introduction}

X-ray imaging techniques are non-destructive and can be selective to a wide range of properties (density, chemical element, chemical bond, strain, surface versus bulk, order versus disorder), with extremely high sensitivity. Their synchrotron radiation (SR) counterpart exhibit many variants that include microspectroscopy (Adams et al., 1998), and three-dimensional (3D) imaging based on absorption, fluorescence (Golosio et al., 2003) or phase contrast. The use of modern SR facilities to perform X-ray imaging leads to added values that are revolutionising the perceptions in many scientific communities of the possibilities offered by SR.

The present paper is devoted to the evolution of synchrotron radiation Xray microtomography, characterized by an increased use of i) phase contrast imaging, ii) high spatial or temporal resolution, iii) in-situ experiments using adapted sample environment, and iv) precise quantitative measurements.

Several successful laboratory microtomographs have been commercially produced over the last years (Rüegsegger et al., 1996, Sasov et al., 1998), but the best images, in terms of spatial resolution, signal-to-noise ratio and quantitative exploitation, are obtained using SR. This results from the high useful intensity (multiplied by $10^{6}$ with respect to usual X-ray generators), the practically parallel and monochromatic incoming beam (avoiding in this way all beam hardening artefacts), the availability of photons spanning the whole range from the infrared to hard X-rays (up to 300-400 keV) and the high degree of coherence of the beam.

In the usual SR microtomographic approach there is no image magnification, and the spatial resolution mainly results from the effective pixel size of the detector, now in the $\mu \mathrm{m}$ range. The total acquisition time can be as fast as $5 \mathrm{~s}$ ("fast tomography") but can also go up to the 40 minutes range, and the recorded data often amounts to several Gigabytes.

\section{Highest possible resolution: an example on cultural heritage rock}

Historic monuments (castles, cathedrals, abbeys, houses, statues and other stone-build structures) are very sensitive to their environment, which may alter or even deeply destroy them. Since they contribute significantly to our historical heritage, we have to protect and eventually restore them. A wide community (architects, scientists, etc.) collaborates in order to protect this historical heritage. In order to optimise the conditions for protecting and restoring the historic monuments, we must understand the mechanisms responsible for their alteration.

One of the first required steps is a complete characterisation of the morphological and topological properties of the porous network of stones. The detailed knowledge of the pore connectivity based on a microscopic description is indeed a prerequisite for the understanding of the water and ionic transfer at the macroscopic scale. The high-resolution microtomography experimental device of the beamline ID19 of the ESRF has been used for this characterisation. This tool provides both the network and the distribution of the different phases. The intense, 
parallel and monochromatic beam allows imaging samples using an effective pixel size as small as $0.28 \mu \mathrm{m}$. Each voxel is characterized by its grey level (that ranges, for an 8 bit image, from 0 to 255), which is directly related to the linear X-ray attenuation coefficient. So, the pores are rather in black, the silica compounds in dark grey and the calcite compounds in light grey as shown on figure 1. An efficient algorithm to segment the $3 \mathrm{D}$ images is in progress in order to quantify these main solid phases and the pore phase by image analysis. This procedure is carried out on quarry and weathered limestones in order to qualify and quantify the alterations.
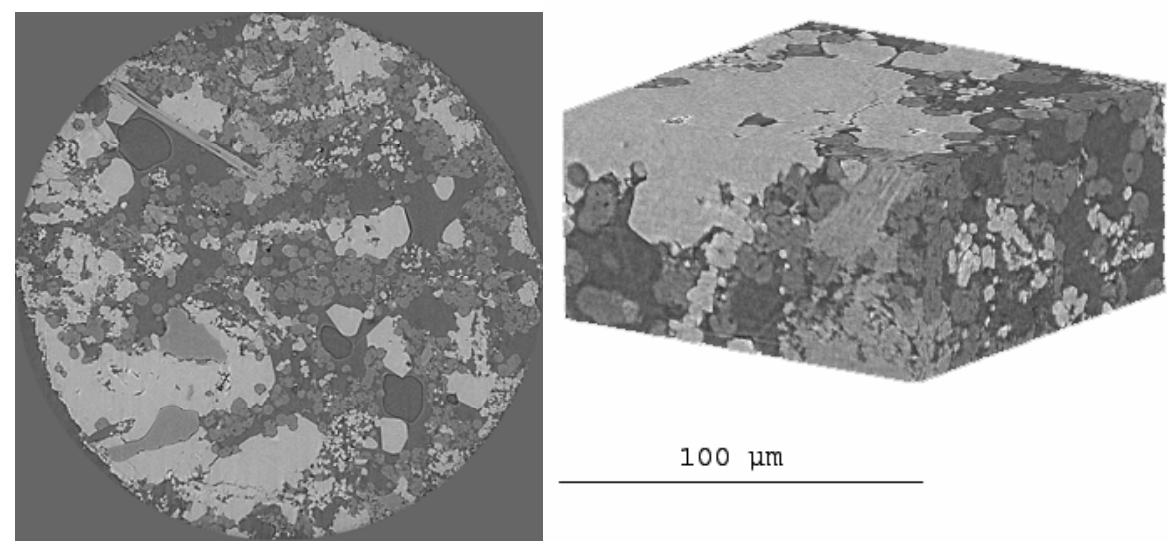

Figure $12 D$ slice (sample diameter: $560 \mu \mathrm{m}$ ) and $3 D$ reconstruction of quarry tuffeau (limestone originating from the Loire valley, France) grey levels allow to distinguish the different components: grey light: calcite, dark grey: silica, black: porosity.

\section{Advances in phase contrast microtomography: an example on a fossil}

The X-ray beams produced at third generation synchrotron radiation facilities exhibit a high degree of spatial coherence. In addition to contrast due to sample absorption, this property induces another type of contrast. Phase contrast images can be recorded by simply varying the sample-to-detector distance ("propagation technique", Cloetens et al., 1999a). The advantage of this imaging technique is its increased sensitivity, in particular for light materials such as polymers, or for composites made up of materials with similar attenuation coefficients (for example $\mathrm{Al}$ and $\mathrm{SiC}$ ). It is thus possible to detect small $\mathrm{SiC}$ particles inside an Al matrix, thanks to an "edge enhancement” contrast mechanism. Phase imaging based on the visualization of the edges (i.e. phase jumps) is not an actually quantitative technique and its spatial resolution is limited by the occurrence of the fringes used to visualize the borders. That is why a more quantitative approach of phase imaging and tomography has been developed. It is based on the combination of microtomographic scans, recorded at different distances. An adapted algorithm allows the holographic reconstruction of the optical phase, well beyond the images of edges. In combination with tomography, the reconstructed quantity is 
the electron density, hence approximately the mass density, in each point of the sample. The highest accessible spatial frequency is determined by the resolution of the detector. This combined quantitative phase mapping and tomography procedure, called holotomography (Cloetens et al., 1999b), provides a more sensitive approach to the characterization of materials on the micrometer scale. A recent paleobotanic application using this technique has given successful results. The samples were Tertiary charophytes from Southern France (Chara costulata) still embedded in a mineral matrix. Figure 2 presents a comparison between an "absorption" slice (obtained by setting the detector only a few $\mathrm{mm}$ apart from the sample) and the result of the holotomographic reconstruction (that requires combining images obtained at various sample-to-detector distances).

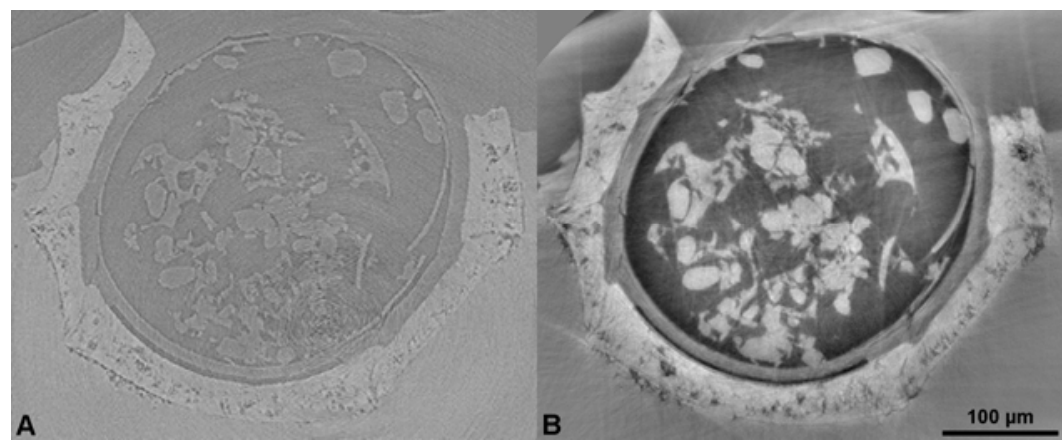

Figure 2: a) Absorption reconstructed slice of a charophyte (linear attenuation coefficient map) b) Same slice in holotomography (density map) (in collaboration with S. Zabler and M. Feist, Institut des Sciences de l'évolution de Montpellier, France)

In the second case, the used technique reveals many features that are invisible or hardly distinguishable on the absorption one. Most of these details can be observed using edge detection mode, but it is impossible to separate (segmentation process) the different parts, according to their grey levels, because only interfaces are enhanced. This was easily performed using holotomographic reconstruction (Tafforeau et al., 2005)

\section{Improved temporal resolution: an example on cement}

Cellulose ethers are organic admixtures usually introduced into mortar formulations in order to induce a substantial increase of the water retention capacity (Pourchez et al., 2006). They therefore prevent water from draining out too quickly from the mortar to the substrate. In this way, more water is retained in the fresh material, which favours cement hydration and thereby increases the mechanical 
strength of the hardened mortar. However, the mechanism of water retention remains poorly understood.

Macroscopic properties of water transport in a fresh mortar mainly depend of local characteristics such as porosity and permeability. Advantages of fast X-ray microtomography are to investigate microstructure of fresh cement material before the setting. Microstructure of hardening cement-based materials was usually characterized by mercury intrusion porosimetry (Guang, 2005), pore segmentation from backscattered electron images (Wong et al., 2006), ultrasonic velocity measurement (Lafhaj et al., 2006) or X-ray microtomography (Burlion et al., 2006) But these techniques do not allow examining the microstructure of fresh mortar. Especially, usual X-ray microtomographic scans are too slow compared to the fast evolution of the porosity in fresh cement-based materials. To follow such a phenomenon fast microtomography is needed. Fast tomography requires short exposure times (obtained by relaxing the monochromaticity of the beam through the use of a multilayer monochromator, or a "pink" beam), and an efficient acquisition chain. A parallel architecture has been implemented to read and store the recorded data, and rotate the sample, while recording the following image.
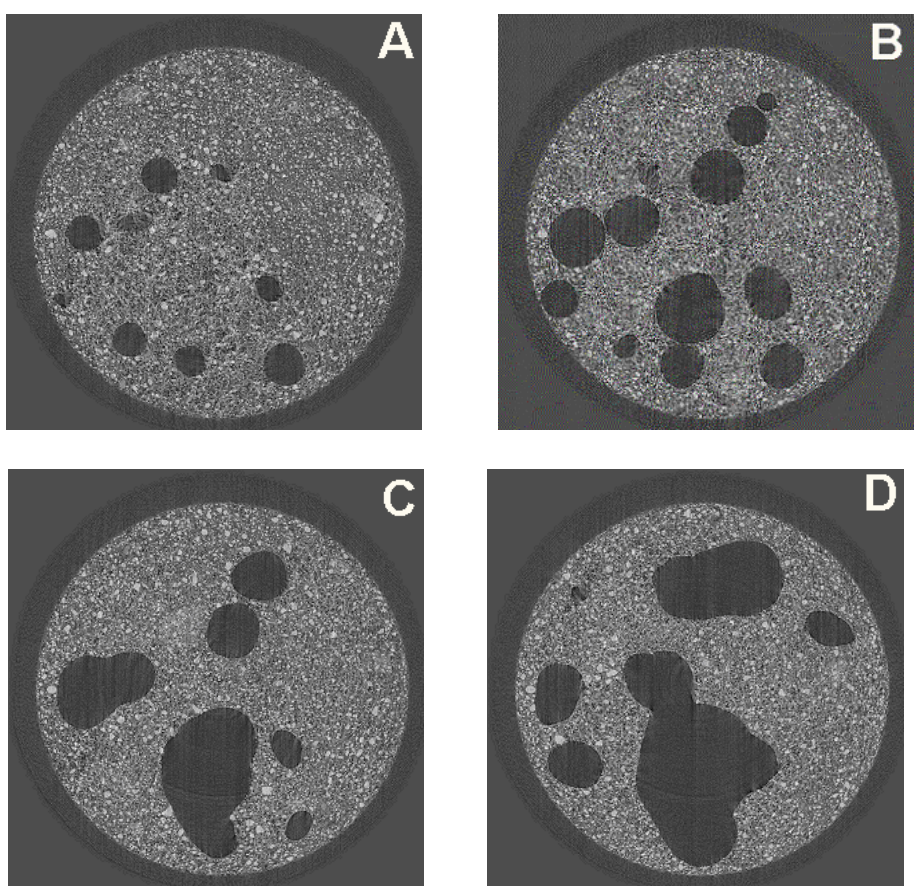

Figure 3 Evolution of pore structure of cement paste without organic admixture (water to cement ratio equal to 0.5) at $16 \mathrm{~min}$ (a), $26 \mathrm{~min}$ (b), $35 \mathrm{~min}$ (c) and $50 \mathrm{~min}$ (d) 
The influence of cellulose ethers on the microstructure of fresh cement pastes was investigated by fast X-ray microtomography (total duration of a scan 1 $\min 35 \mathrm{~s}$ at a resolution of $2.8 \mu \mathrm{m})$. The case of the polymer named U2 is characteristic of the impact of cellulose ethers on the porosity of fresh cement paste. Figures 3 and 4 show that contrary to non-admixed cement materials, in presence of polymer, a substantial increase of the porosity was observed. Moreover, the size of spherical air voids was significantly smaller and more numerous in presence of polymers. This experiment shows that fast X-ray microtomography is a remarkable investigation tool to elucidate microstructure of polymer modified cement paste.
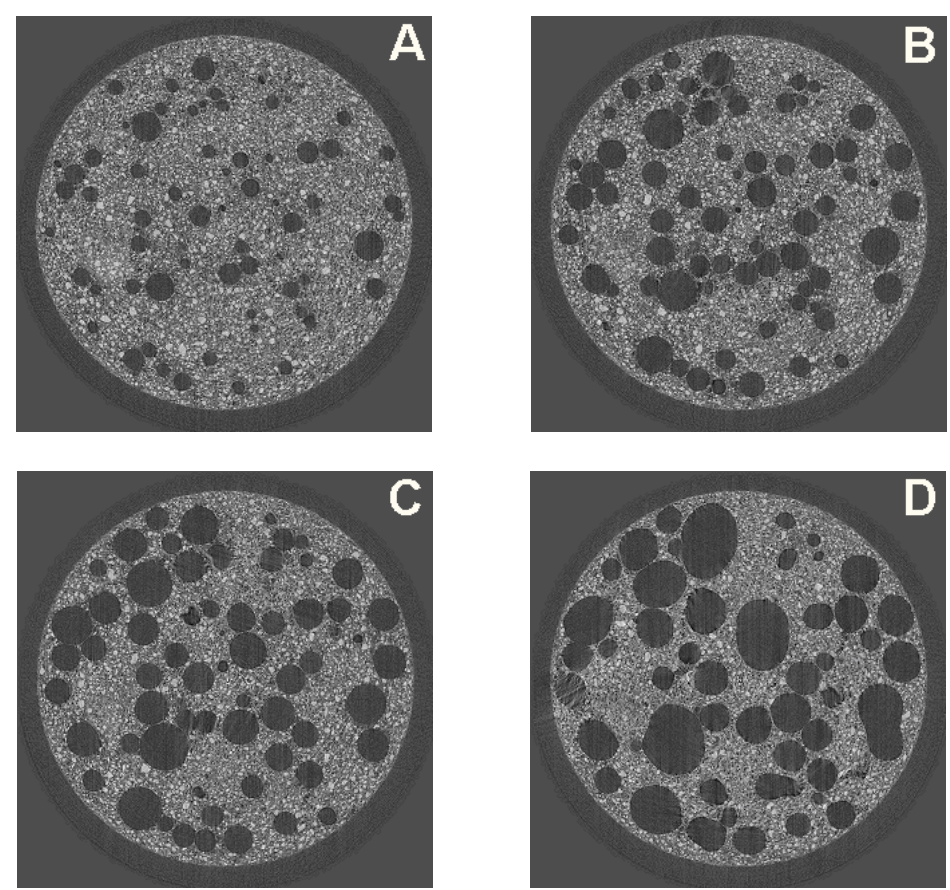

Figure 4 Evolution of pore structure at the same level in the stack as in figure 3 of a cellulose ether modified cement paste (water to cement ratio equal to 0.5) at $16 \mathrm{~min}$ (a), 26 min (b), 35 min (c) and 50 min (d)

\section{Present state and future developments}

In many cases the scientific data have to be extracted from a statistically relevant number of samples. This is the case, for instance, for the quantification of the action of a drug on osteoporosis, where a series of bones of animals submitted to the drug 
are imaged to obtain a result going beyond the variability of reaction of the individuals. For this kind of experiments it is important to automate as much as possible the acquisition. An automation device has been developed and was used, for instance, when analysing paper microstructure (Thibault et al., 2005). A large number of different samples were investigated without having to re-enter into the hutch, thus without changing the environmental conditions of the beamline optics and the specimen. For such high-resolution experiments on samples that are very sensitive to small hygrometry changes, image quality is highly improved by controlling in this way the experimental conditions.

The SR parallel beam configuration, imposes, to change the spatial resolution, to modify the effective pixel size of the detector. Several optic-scintillator ensembles were developed at the ESRF, with pixel sizes going from 40 down to $0.28 \mu \mathrm{m}$. They mount on the special FReLoN (Fast Readout Low Noise) CCD camera designed for the ESRF work. A drawback associated with large number of different configurations is the increase of the mounting time. A medium-resolution microtomograph will be available, in addition to the high resolution one, by the end of this year, to reduce as much as possible the mounting time. Along the same line, a "revolver" type optic is being designed to cover pixel sizes from 3 to $0.17 \mu \mathrm{m}$.

\section{Academic and industrial access}

The academic access to ESRF is performed through the submission of proposals (before $1^{\text {st }}$ of March and $1^{\text {st }}$ of September each year). A proposal describes a scientific project where the use of SR is actually required. A committee, composed of external expert members ranks these projects and recommend allocating beamtime to the highly ranked ones.

A number of industrial companies need to use SR microtomography to solve some of the problems they encounter. They can either access to the beamline through collaboration with academic research groups and, as previously mentioned, peer-reviewed proposals, or they buy beam time and expertise. In this last case the use of the ESRF includes confidentiality, rapid access and full service. The service proposed by the ESRF includes the preparation of the experiment (feasibility, preparation, planning), the experiment itself and the volume reconstructions. Most of the industrial results are confidential and cannot be shown as examples.

\section{Conclusion}

X-ray computed microtomography is an invaluable tool to obtain threedimensional information on a large variety of materials, and in particular on geophysics topics. The use of a modern SR source opens up new possibilities. The 
most important features, as far as absorption microtomography is concerned, are the very broad choice available in the photon energy (typically between 7 and $60 \mathrm{keV}$, but also up to $200 \mathrm{keV}$ on the ID15 high energy beamline), the quantitative evaluation of the experimental data made possible by the beam being monochromatic and parallel, and the improved spatial resolution, now below 1 micron. These techniques are well adapted to in-situ experiments, where the material, in an adequate sample environment, is imaged as a function of an external parameter. The very small angular size of the source provides, in an instrumentally simple way, phase images, which reveal phenomena hardly visible by other means. Other approaches, using focussed beams, for magnified tomography and highresolution fluorescence mapping, are under development (Hignette et al., 2005).

\section{Acknowledgements}

The authors would like to thank René Chagnon and David Fernandez Carreiras for their respectively mechanical and software skills in the automation system development.

\section{Bibliography/References}

Adams F, Janssens K, Snigirev A, J. Analytical Atomic. Spectrometry 1998; 13: 319

Burlion N., Bernard D. and Chen D., "X-ray microtomography: Application to microstructure analysis of a cementitious material during leaching process" Cement and Concrete Research, Volume 36, Issue 2, February 2006, Pages 346-357

Cloetens P., Ludwig W., Baruchel J., Guigay J.P., Rejmankova-Pernot P., Salomé-Pateyron M., Schlenker M., Buffière J.Y., Maire E., Peix G., "Hard X-ray phase imaging using simple propagation of a coherent synchrotron radiation beam.” J. Phys. D: Appl. Phys.32, A145A151, 1999a

Cloetens P., Ludwig W., Baruchel J., Van Dyck D., Van Landuyt J., Guigay J.P., Schlenker M., "Holotomography: quantitative phase tomography with micrometer resolution using hard synchrotron radiation X-rays”, Appl. Phys. Lett., 75, 2912-2914, 1999b

Golosio B, Simionovici A, Somogyi A, Lemelle M, Chukalina M, Brunetti A, J. Appl. Phys. 2003; 94: 145

Guang Ye, "Percolation of capillary pores in hardening cement pastes”, Cement and Concrete Research, Volume 35, Issue 1, January 2005, Pages 167-176

Hignette O., Cloetens P., Rostaing G., Bernard P., Morawe C., "Efficient sub 100 nm focusing of hard X-rays”, Review of Scientific Instruments, 76, 063709, 2005 
Lafhaj Z., Goueygou M., Djerbi A. and Kaczmarek M., “Correlation between porosity, permeability and ultrasonic parameters of mortar with variable water / cement ratio and water content”, Cement and Concrete Research, Volume 36, Issue 4, April 2006, Pages 625-633

Pourchez J., Peschard A., Grosseau P., Guyonnet R., Guilhot B. and Vallée F., "HPMC and HEMC influence on cement hydration”, Cement and Concrete Research, Volume 36, Issue 2, February 2006, Pages 288-294

Rüegsegger P, Koller B, Müller R, Calcif. Tiss. Int., 1996; 58: 24

Sasov A, Van Dyck D, Journal of Microscopy 1998; 191: 151

Tafforeau P., Boistel R., Boller E., Bravin A., Brunet M., Chaimanee Y., Cloetens P., Feist M., Hoszowska J., Jaeger J.-J., Kay R. F., Lazzari V., Marivaux L., Nel A., Nemoz C.,

Thibault X., Vignaud P., Zabler S., “Applications of X-ray synchrotron microtomography for non-destructive 3D studies of paleontological specimens”, Applied Physics A, 2006, 83, 195202

Thibault X., Rolland du Roscoat S., Cloetens P., Boller E., Chagnon R., Bloch J.F., "Experimental improvements for micro-tomography of paper and board”, Materials Characterisation Conference, Portland, 2005

Wong H.S., Head M.K. and Buenfeld N.R., "Pore segmentation of cement-based materials from backscattered electron images”, Cement and Concrete Research, 2006, 36, 1083-1090 